\title{
Parthenogenetic haploid embryonic stem cells efficiently support mouse generation by oocyte injection
}

\author{
Cell Research (2016) 26:131-134. doi:10.1038/cr.2015.132; published online 17 November 2015
}

\section{Dear Editor,}

Mammalian haploid embryonic stem cells (haESCs) have been recently generated from parthenogenetic and androgenetic embryos [1, 2]. Both parthenogenetic haESCs (PG-haESCs) and androgenetic haESCs (AGhaESCs) can be used for cell-based reverse and forward genetic screens on a whole-genome scale [3, 4]. AGhaESCs, after intracytoplasmic injection into oocytes (referred to as ICAHCI), can be used as a sperm replacement to produce healthy semi-cloned (SC) mice at a rate of $\sim 2 \%$ of transferred embryos $[5,6]$. Interestingly, after inhibiting the expression of two paternally imprinted genes (H19 and Gtl2) in AG-haESCs by removal of their differentially methylated DNA regions (DMRs), these cells can efficiently and stably support the generation of healthy SC pups at a rate of $\sim 20 \%$ [7]. Nevertheless, the feasibility of using PG-haESCs for generation of SC mice via oocyte injection has not yet been demonstrated. We reason that, if PG-haESCs can support the efficient generation of SC mice, it is not necessary to make AGhaESCs by injection of sperm heads into enucleated oocytes, a complex procedure that is very difficult to handle. In this study, we show that PG-haESCs exhibit highly similar gene expression profiles to those of AGhaESCs, and after removal of $H 19$ and Gtl2 DMRs, DKO-PG-haESCs can efficiently produce SC pups. Thus, our study establishes haploid cells from oocytes that have the ability to efficiently produce mice by injection into oocytes.

To derive PG-haESCs, we chemically activated mature oocytes (C57BL/6 background) and selected embryos with only one female pronucleus for further in vitro culturing to the blastocyst stage. A total of 79 parthenogenetic haploid blastocysts were cultured in a standard embryonic stem cell (ESC) culture system supplemented with 2i (MEK and GSK inhibitors) [8]. 38 ESC lines were generated and subjected to multiple rounds of FACS to enrich for haploid 1C cells, and 6 PG-haESC lines (referred to as PGH-1 to PGH-6) were established (Figure 1A and Supplementary information, Figure S1A and S1B). We then tested whether PG-haESCs could support full-term development of mouse embryos upon injection into mature oocytes. To this end, we performed intracytoplasmic PG-haESCs injection (ICPHCI). Briefly, FACS-enriched cells containing one set of chromosome were expanded in ESC culture medium for several days and arrested at the $\mathrm{M}$ phase by treatment with 0.05 $\mathrm{mg} / \mathrm{ml}$ demecolcine for $8 \mathrm{~h}$ before injection. Each nucleus from M-phase haploid cells was injected into a MII-arrested oocyte to make an SC embryo as previously reported [6]. We found that PG-haESCs failed to support embryonic development after injection into oocytes (Supplementary information, Table S1). This result is not surprising as ICPHCI-derived SC embryos, containing two copies of female genomes, were actually parthenogenetic diploid embryos that cannot develop to term in vivo [9].

Next, we attempted to reveal the differences between PG-haESCs and AG-haESCs by comparing the gene expression profiles of PG-haESCs with those of AGhaESCs and normal diploid control ESCs. RNA sequencing (RNA-seq) data revealed a high correlation $(r=0.99)$ between PG-haESCs and AG-haESCs based on all expressed genes or all imprinted genes (Figure 1B and 1C and Supplementary information, Figure S1C-S1E). To further assess epigenetic inheritance, we performed bisulfite-sequencing analysis to determine the DNA methylation profiles of DMRs of two paternally imprinted genes, Gtl2 and H19, and two maternally imprinted genes, Snrpn and Peg1. The results showed that the DMRs of $H 19$ and Gtl2 were free of methylation (Supplementary information, Figure S1F), reflecting the parthenogenetic origin of the haploid cells. However, methylation at $\mathrm{Sn}$ rpn and Peg1 DMRs, which should be largely intact due to their oocyte origin, was also absent (Figure 1D and Supplementary information, Figure S1G). Interestingly, among six tested PG-haESC lines, four lost methylation at Snrpn and Peg1 DMRs at early passages and another two cell lines, although retaining hypermethylation at the Snrpn DMR at an early passage, gradually lost methylation during cell passaging (Supplementary information, 
Figure $\mathrm{S} 1 \mathrm{H})$. Taken together, loss of imprinting at maternally imprinted loci happens quickly during PG-haESC derivation and in vitro culture, leading to similar DNA methylation and gene expression patterns to those of AG-

\section{haESCs.}

Recently, we have shown that a wild-type AG-haESC line, which almost completely lost its ability to produce normal SC mice by ICAHCI, regained the capacity for
A

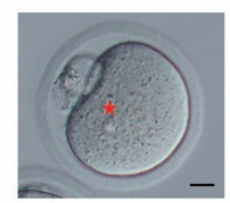

PGH-1 p20
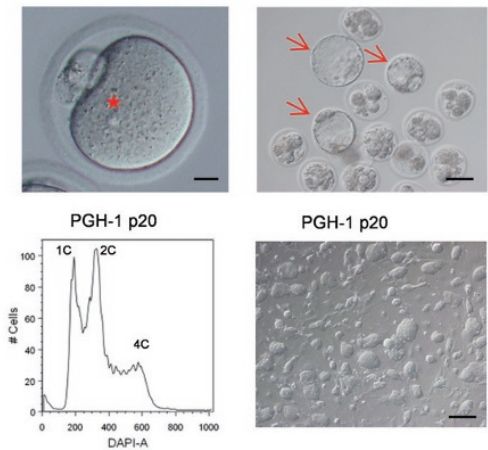

PGH-1 p20

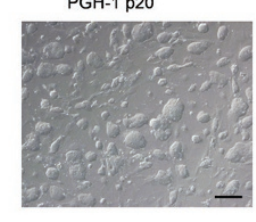

B

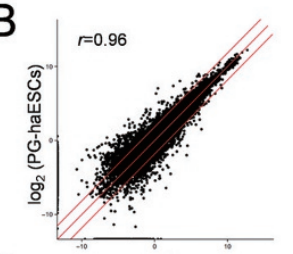

C

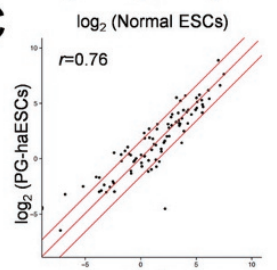

$\log _{2}$ (Normal ESCs)

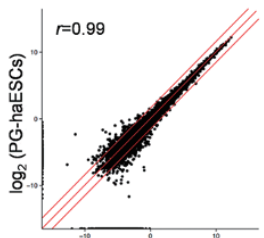

$\log _{2}$ (AG-haESCs)

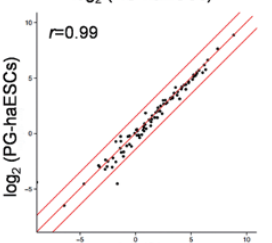

$\log _{2}$ (AG-haESCs)
D

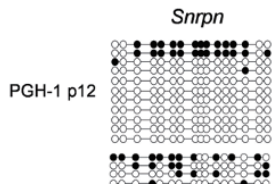

PGH-6 p9

98

MEF p1
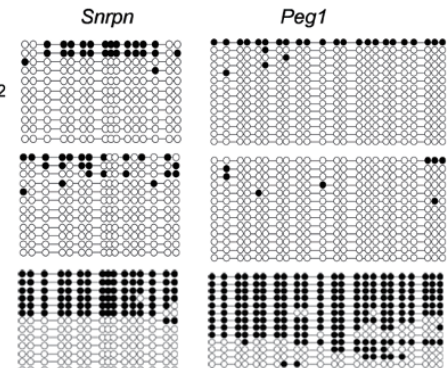

E
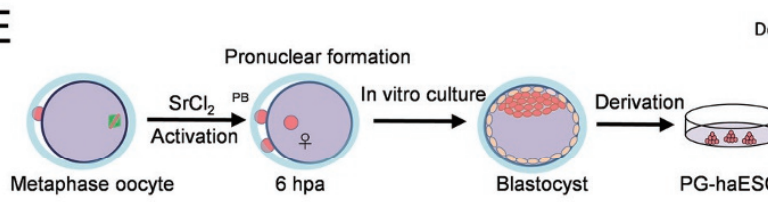

Deletion of H19-DMR

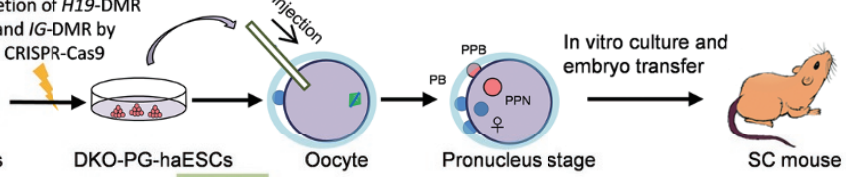

Metaphase oocyte

6 hpa
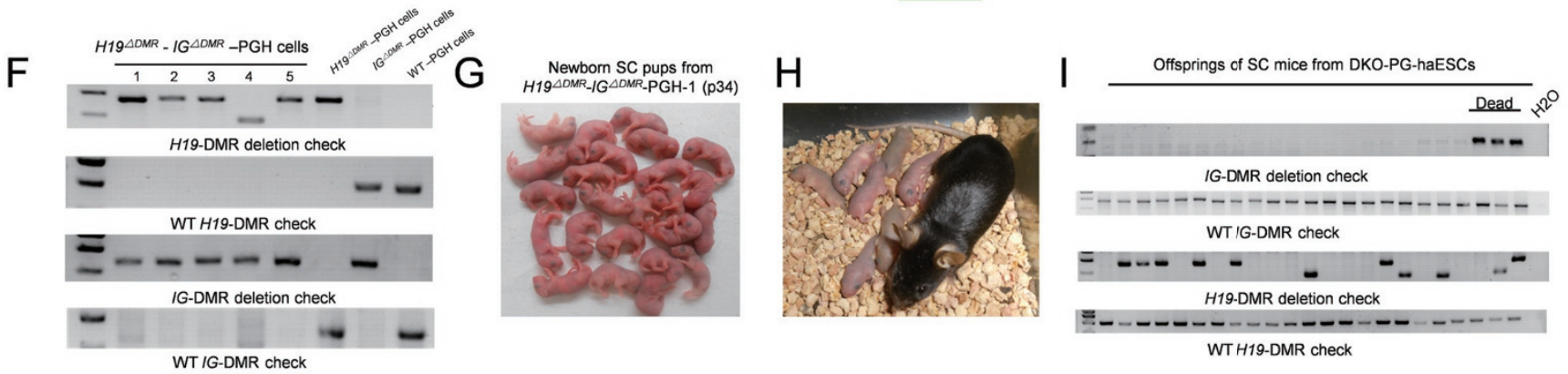

WT H19-DMR check

Figure 1 PG-haESCs harboring both H19-DMR and IG-DMR deletions efficiently support the production of live SC pups. (A) Generation of PG-haESCs. Upper left, the image of parthenogenetically activated oocytes containing only one pronucleus (scale bar, $25 \mu \mathrm{m}$ ). Upper right, parthenogenetic blastocysts (scale bar, $100 \mu \mathrm{m}$ ). Lower left, establishment of a haploid cell line after multiple rounds of FACS enrichment for haploid cells (represented by PGH-1). A DAPI filter was used to detect the signal of Hoechst-stained DNA. Lower right, phase-contrast image of ESCs derived from one parthenogenetic blastocyst (scale bar, $200 \mu \mathrm{m}$ ). The asterisk indicates that only one pronucleus exists in the activated oocyte. Arrows indicate the parthenogenetic blastocysts that are used for ESC derivation. (B) Scatter plot of $\log _{2}$-transformed average gene expression profiles. Global gene expression profiles of PG-haESCs, AG-haESCs and diploid ESCs were obtained from RNA-seq analysis ( $r$ is the Pearson's correlation coefficient; red lines indicate twofold upregulation and downregulation). To avoid the influence of diploidized cells on the expression profile, we collected samples after FACS of cells at the G1/G0 phase. (C) Scatter plot analysis of gene expression profiles of the tested cell lines based on all imprinted genes. (D) Methylation states of the DMRs of Snrpn and Peg1 in two PG-haESC lines. Open and filled circles represent unmethylated and methylated CpG sites, respectively. (E) Diagram of SC mice generated by ICPHCI using PG-haESCs. hpa, hours post activation. PPN, pseudopronucleus formed from injected PG-haESC. PB, polar body. PPB, pseudopolar body. (F) Genotyping analysis of DKO-PG-haESCs. These cell lines were generated by deletion of both IG and H19 DMRs in WT PG-haESCs. Note that different sized bands can be observed in H19-DMR deletion analysis because using two sgRNAs to remove the 3.8-kb H19 DMR will result in cell lines carrying different sequences around the H19-DMR cleavage sites due to random DNA repair followed by CRISPR-Cas9-mediated cleavage. (G) SC pups generated by ICPHCl using DKO-PG-haESCs (represented by $H 19^{\triangle \mathrm{DMR}}-\mathrm{I}^{\triangle \mathrm{DMR}}-\mathrm{PGH}-1$ cells (passage 34)). (H) A female SC mouse derived from DKO-PG-haESCs and its progeny. (I) Genotyping analysis of the progeny of SC mice derived from DKO-PG-haESCs. Pups carrying mutant IG-DMR or mutations in both H19 and IG DMRs died shortly after birth. Note that different sized bands are observed in H19-DMR deletion analysis because offsprings were born from two SC mothers produced from two DKO-PG-haESC lines carrying different sequences around the H19-DMR cleavage sites. 
high-efficiency production of SC mice after removal of the H19 DMR and intergenic germline-derived $(I G)$ DMR (which regulates the expression of the Dlk1-Gtl2imprinted cluster) [7]. Because PG-haESCs exhibited similar gene expression and DNA methylation patterns to those of AG-haESCs, we asked whether PG-haESCs could also gain the ability to produce live SC mice through ICPHCI (Figure 1E). To this end, we adopted the same strategy reported in our previous study to remove $H 19$ and $I G$ DMRs in PG-haESCs. Briefly, we individually designed two sgRNAs to remove the 4.15$\mathrm{kb} I G$-DMR and the 3.8-kb H19-DMR and transfected the pX330-mCherry plasmids expressing Cas9 and sgRNAs into four independent PG-haESC lines (Supplementary information, Figure S2A). PG-haESCs expressing mCherry, in which the CRISPR-Cas9 system was successfully transfected, were enriched and plated for cell line derivation. A total of 91 haploid cell lines were generated, and 24 and 17 cell lines carried the $I G$-DMR deletion (termed $I G^{\Delta \mathrm{DMR}}$-PGH) and H19-DMR deletion (termed $H 19^{\triangle \mathrm{DMR}}-\mathrm{PGH}$ ), respectively (Supplementary information, Figure S2B-S2D). 44 cell lines carried deletions of both DMRs (termed $H 19^{\Delta \mathrm{DMR}}-I G^{\Delta \mathrm{DMR}}$-PGH or DKO-PG-haESCs; Figure 1F). Methylation analysis of Snrpn DMR showed that $H 19$ and $I G$ DMR deletions did not change the methylation state of this maternally imprinted DMR (Supplementary information, Figure S2E) in haploid cells, suggesting that DKO-PG-haESCs exhibit a similar DNA methylation pattern to that of DKOAG-haESCs.

Finally, we performed ICPHCI experiments using PGhaESCs carrying one DMR deletion or double DMR deletions as donors. Consistent with our previous observations in AG-haESCs carrying one DMR deletion, while PG-haESCs carrying only H19-DMR deletion could efficiently support the full-term development of SC embryos at a rate of $2.6 \%$ of transferred embryos, PG-haESCs carrying only $I G$-DMR deletion led to more growth-retarded pups than normal-sized pups $(4.1 \%$ vs $1.4 \%$ of transferred embryos; Supplementary information, Table S1 and Figure S2F and S2G). Strikingly, ICPHCI using DKO-PG-haESCs yielded $15.5 \%$ of SC embryos that developed to term and generated alive SC pups of normal size (Figure 1G and Supplementary information, Table $\mathrm{S} 1)$. Interestingly, normal-sized SC pups were obtained at a higher frequency from ICPHCI using cells of late passages, supporting our early observation of gradual loss of methylation at maternally imprinted genes during cell passaging (Supplementary information, Table S1 and Figure S1H). A total of 158 normal-sized SC pups were born in this study. These pups could grow up to adulthood and reproduced normally (Figure $1 \mathrm{H}$ and Supple- mentary information, Figure S2H-S2J). Alive offspring of SC mice carried mutant H19-DMR or no mutations, while dead offspring carried mutant $I G$-DMR or mutations in both $H 19$ and $I G$ DMRs (Figure 1I), which is consistent with previous results that maternal transmission of the $I G$-DMR deletion induced postnatal or neonatal lethality [10]. Taken together, these data further demonstrate that PG-haESCs of late passages exhibit a similar imprinting pattern to that of AG-haESCs and they could gain the capacity for high-efficiency production of SC mice via ICPHCI upon removal of DMRs of two paternally imprinted genes.

The developmental potential of PG-haESCs has been tested through generation of reconstructed embryos containing sperm heads and nuclei of PG-haESCs that were used to replace the genome of oocytes [11]. However, the birth rate was extremely low (2 from 290) and only one pup grew up to adulthood. One potential reason could be the loss of maternal imprints during cell passaging as we observed in this study (Figure 1C, 1D and Supplementary information, Figure $\mathrm{S} 1 \mathrm{G}$ and $\mathrm{S} 1 \mathrm{H}$ ), resulting in a different epigenetic state in PG-haESCs comparing with that in oocytes. Therefore, nucleus of PG-haESC may not be a suitable replacement of the oocyte genome. In this study, we have demonstrated that PG-haESCs indeed lost the maternal imprints during cell passaging, exhibited a similar imprinting pattern to that of AG-haESCs, and thus can obtain the capacity for high-efficiency production of SC mice via ICPHCI upon removal of DMRs of two paternally imprinted genes. Our findings advance the haploid ESC technology since generation of haploid cells from oocytes avoids application of nuclear transfer, a complex procedure that is required for generation of haploid cells from sperm. One intriguing application of the technology is the generation of gene-modified animals via ICPHCI in other species, for which haploid ESCs have been obtained from oocytes, but may be very difficult to obtain from sperm, such as the monkey [12].

\section{Acknowledgments}

We thank Wei Bian, Xuedong Wang, and Fang Zhang for support with cell sorting and Drs Yuelei Chen and Xiaoyan Ding from the Stem Cell Core Facility at SIBCB for support with cell cultures. This study was supported by the Ministry of Science and Technology of China (2014CB964803, 2015AA020307 and 2013CB967103), the National Natural Science Foundation of China (91319310 and 31225017), the Chinese Academy of Sciences (XDA01010403), and the Shanghai Municipal Commission for Science and Technology (12JC1409600 and 13XD1404000).

Cuiqing Zhong ${ }^{1,2,3, *}$, Zhenfei Xie ${ }^{1,2,3, *}$, Qi Yin ${ }^{1,2,3,{ }^{*}}$, Rui Dong ${ }^{3,4}$, Suming Yang ${ }^{1,2,3}$, 


\section{Yuxuan $\mathrm{Wu}^{1,2}$, Li Yang ${ }^{4}$, Jinsong $\mathrm{Li}^{1,2}$}

${ }^{I}$ Group of Epigenetic Reprogramming, State Key Laboratory of Cell Biology, Institute of Biochemistry and Cell Biology, Shanghai Institutes for Biological Sciences, Chinese Academy of Sciences, Shanghai 200031, China; ${ }^{2}$ Shanghai Key Laboratory of Molecular Andrology, Institute of Biochemistry and Cell Biology, Shanghai Institutes for Biological Sciences, Chinese Academy of Sciences, Shanghai 200031, China; ${ }^{3}$ University of Chinese Academy of Sciences, Beijing 100049, China; ${ }^{4}$ Key Laboratory of Computational Biology, CAS-MPG Partner Institute for Computational Biology; CAS Center for Excellence in Brain Science, Shanghai Institutes for Biological Sciences, Chinese Academy of Sciences, Shanghai 200031, China

*These three authors contributed equally to this work.

Correspondence: Jinsong $\mathrm{Li}$

E-mail: jsli@sibcb.ac.cn

\section{References}

1 Shi L, Yang H, Li J. Protein Cell 2012; 3:806-810.

2 Wutz A. Annu Rev Cell Dev Biol 2014; 30:705-722.

3 Elling U, Taubenschmid J, Wirnsberger G, et al. Cell Stem Cell 2011; 9:563-574.

4 Leeb M, Wutz A. Nature 2011; 479:131-134.

5 Li W, Shuai L, Wan H, et al. Nature 2012; 490:407-411.

6 Yang H, Shi L, Wang BA, et al. Cell 2012; 149:605-617.

7 Zhong C, Yin Q, Xie Z, et al. Cell Stem Cell 2015; 17:221-232.

8 Ying QL, Wray J, Nichols J, et al. Nature 2008; 453:519-523.

9 McGrath J, Solter D. Cell 1984; 37:179-183.

10 Lin SP, Youngson N, Takada S, et al. Nat Genet 2003; 35:97-102.

11 Wan H, He Z, Dong M, et al. Cell Res 2013; 23:1330-1333.

12 Yang H, Liu Z, Ma Y, et al. Cell Res 2013; 23:1187-1200.

(Supplementary information is linked to the online version of the paper on the Cell Research website.) 